\title{
Understanding Intestinal Vulnerability to Perforation in the Extremely Low Birth Weight Infant
}

\author{
PHILLIP V. GORDON \\ Department of Pediatrics, Ochsner Health System, New Orleans, Louisiana, 70121
}

\begin{abstract}
Spontaneous intestinal perforation (SIP) occurs commonly in extremely low birth weight (ELBW) infants. Our understanding of its etiologies has improved dramatically over the last decade. Included in this comprehension is an ongoing reconciliation of the iatrogenic risk factors, the microbiology, and the histopathology. The latter shows focal perforations with necrosis of the muscularis externa and no sign of ischemic damage (typically characterized by mucosal necrosis in the preterm bowel). Associations include extreme prematurity, early postnatal steroids (EPS), early use of indomethacin (EUI), and two common pathogens (Candida and Staphylococcus epidermis). Animal models of SIP suggest that all risk factors converge on a common collection of signaling pathways: those of nitric oxide synthases (NOS), insulin-like growth factors (IGFs), and epidermal growth factors (EGFs). Many of these factors skew trophism of the ileum (defined as thinning of the submucosa concomitant with hyperplasia of the muscosa). Global depletion of NOS is associated with disturbed intestinal motility and diminished transforming growth factor-alpha (TGF- $\alpha$ ) in the muscularis externa. This constellation of insults seems to make the distal intestine vulnerable to perforation during recovery of motility. (Pediatr Res 65: 138-144, 2009)
\end{abstract}

\section{WHY SPONTANEOUS INTESTINAL PERFORATION IS NOT NECROTIZING ENTEROCOLITIS}

Before any serious discussion of spontaneous intestinal perforation (SIP) etiology can commence, it is necessary to dispense with the idea that SIP and necrotizing enterocolitis (NEC) are manifestations of the same disease, but representative of two different ends of the continuum $(1,2)$. The evidence for such an argument has never been compelling, essentially based on a belief that it must be so because they occur in the same patient population and because management is roughly similar. The same can be said about syphilis and gonorrhea. They affect the same patient populations, affect the same organs and, if you are creative, they can be managed with the same antibiotic regimen. Few would argue these diseases are the same.

In contrast, the evidence that SIP is distinct from NEC is very strong. The histopathology of SIP has been well documented by four independent groups on nearly as many continents (3-6). It looks nothing like NEC. The mucosa is robust rather than necrotic. There are focal perforations, most commonly in the ileum, which are associated with isolated areas of necrosis in the muscularis externa about $30 \%$ of the time (7).

Received April 16, 2008; accepted August 16, 2008.

Correspondence: Phillip V. Gordon, M.D., Ph.D., Ochsner Children's Health Center, 1514 Jefferson Highway, New Orleans, LA 70121; e-mail: pvgordon@ochsner.org
There is no inflammation and no evidence of ischemia (a hallmark of NEC), particularly so in cases that are diagnosed in a timely fashion. The progression of disease with SIP does not follow Bell's staging for NEC (8). That is to say, with the majority of SIP cases, pneumatosis cannot be found on radiographs either before or after perforation. Finally, infants who acquire SIP are smaller, younger, and acquire the disease at a different time of life than infants who acquire NEC with perforation $(9,10)$. They also are unlikely to be fed (another well known risk factor for NEC) and more likely to have early postnatal steroids (EPS, a variable that has been shown to be protective for NEC) $(11,12)$. In short, there is little about SIP that is consistent with the diagnosis of NEC except that it does affect the bowel of preterm neonates and it does require the services of a surgeon.

\section{WHAT ARE THE RISK FACTORS FOR SIP THAT NEONATOLOGISTS CAN AVOID?}

Early postnatal steroids. During the mid 1990s, there were many multicenter, randomized-controlled trials (RCTs) of early postnatal dexamethasone (EPD) for prevention of chronic lung disease. Continued enrollment in these trials was challenged by two manuscripts that showed an association between EPD and SIP $(3,13)$. The first by Gordon et al. (3) was a retrospective cohort comparison that included histopathology and negative culture, and pathogen staining data. The second by Garland et al. (13) was a RCT of EPD, which showed an association between early SIP (within the first week of life) and EPD, but failed to show a global effect via intention-to-treat analysis. However, the study suffered from off-label steroid use and this effect was not investigated. From that point forward, no RCT investigating early postnatal steroids (EPS) (either dexamethasone or hydrocortisone) made it past the point of their interim safety analyses without being stopped (14-23). Previous trials, which had been completed, included older gestation, larger birth weight infants (and presumably had a lower SIP incidence) (24,25). Using the techniques of meta-analysis to look at the effect of EPS in all RCTs that enrolled extremely low birth weight (ELBW) infants for all such studies done before 2008, the combined

Abbreviations: ELBW, extremely low birth weight; EUI, early use of indomethacin; EPD, early postnatal dexamethasone; EPS, early postnatal steroids; NEC, necrotizing enterocolitis; NSAID, non-steroidal anti-inflammatory drug; PDA, patent ductus arteriosus; RCT, randomized controlled trial; SIP, spontaneous intestinal perforations 
odds-ratio for EPS and SIP was found to be 2.0 and the number needed to harm was 31 (7). However, it is important to realize that many early RCTs did not include SIP as an outcome that was prospectively followed; a practice that can bias studies toward under reporting. When studies only with predefined SIP were used in the meta-analysis, the odds ratio was 2.7 and the number needed to harm was 14 (7). Although there was early resistance to the concept that EPD was causally associated with steroids $(26,27)$, this relationship is now widely accepted. The combined associations of the adverse neurodevelopmental outcomes and increased risk of SIP has lead to the abandonment of EPD as a viable prophylactic strategy in neonatology (28-30).

The use of early postnatal hydrocortisone remains controversial. Although dexamethasone has a broader effect and higher potency, the use of hydrocortisone is generally meant to supplement infants who are adrenally insufficient. Watterberg et al. have previously demonstrated that early adrenal insufficiency is associated with an increased incidence of chronic lung disease in ELBW infants (22). Likewise, studies have shown that relatively low dosage hydrocortisone in the first day of life can modulate hypotension in ELBW infants that are refractory to pressors $(16,17)$. These findings suggest that there is still room for study of cortisol replacement in the clinical arena but that perhaps EPD is best suited for animal models of SIP.

Early use of indomethacin. Oral indomethacin has been associated with SIP in case reports since before surfactant became available (31-33). However, intravenously indomethacin in the presurfactant era was not only considered safe, its prophylactic administration approached the standard of care in VLBW infants. Two RCTs forced the neonatal community to re-examine early use of indomethacin (EUI-administered within the first $72 \mathrm{~h}$ of life). First, the RCT by Starke et al. utilizing EPD was stopped at its interim safety analysis after an increased incidence of SIP was noted in the treatment group (15). Post hoc analysis indicated that EUI was also strongly associated with SIP-particularly so-in combination with dexamethasone. This was a very troublesome finding and coupled with the neurodevelopmental sequelae of EPD lead to the discontinuation of routine dexamethasone in premature infants. The subsequent trial by Watterberg et al. showed the same association between EUI and EPS (23). The decision to terminate the trial early was questioned in some circles (26) and the use of purely prophylactic indomethacin is still common because of the belief that the practice reduces intraventicular hemorrhage. One reason for this was the TIPP trial, a RCT that actually found no reduction of intraventricular hemorrhage with indomethacin prophylaxis, but found no difference in SIP between indomethacin-treated and nontreated cohorts (34). This RCT-restricted indomethacin use to the first day of life, with most infants receiving indomethacin within the first $12 \mathrm{~h}$ of life and they reported SIP as a secondary outcome. Shortcomings of this trial include: individual centers that reported SIP as an adverse outcome and off-label steroid use that was not recorded. Thus, although the SIP rates between prophylactic and control cohorts were not different, the TIPP trial may not have shown an accurate assessment of indomethacin risk. To address this issue, Attridge et al. used a national dataset to look for an association between indomethacin and SIP (12). Using multivariate regression analysis and two different derivations, they found significant associations between EUI and SIP. However, they did not find an association with indomethacin given after day of life four. In addition, along with EUI, they also found variables, such as exogenous steroids, that transport from an outside facility, a pressors, and a patent ductus arteriosus (PDA) to be associated with SIP-all variables associated with stress or EPS. These findings leave open the possibility that indomethacin may require steroids (either exogenous or endogenous) to generate SIP.

\section{WHAT ARE THE RISK FACTORS FOR SIP THAT NEONATOLOGISTS CANNOT AVOID?}

Chorioamnionitis/funisitis/peritonitis. Nine studies have reported pathogens associated with SIP (6,35-42). On average, approximately $40 \%$ of the cases will grow Candida and $20 \%$ will grow Staphylococcus epidermis (7). The most common site for a positive culture is from peritoneal swabs at the time of surgery, but one of these studies reports positive blood cultures as the dominant result (35). In this same study, they also reported a $40 \%$ incidence of funisitis and $12.5 \%$ positive Candida cultures for the affected placentas of infants with SIP versus none in a matched control group (a significant finding). This is a controversial finding, because in most cases with positive Candida peritoneal cultures, the presumption is that the organism came from luminal flora and the infants are often not treated with antifungals unless there are signs of systemic infection. This also creates something of a theoretical conundrum. Chorioamnionitis may contribute to SIP indirectly through fetal stress, as suggested by the Prophet study where infants with high enogenous cortisol levels were more likely to have SIP (23). Conversely, if funisitis is associated with greater risk, there may be additional, more direct mechanisms that we have yet to elucidate.

Extreme prematurity. Although SIP can occur at any age, examination of a national data set reveals that there are two distinct subsets of infants who acquire the disease. Those who acquire SIP in the first few days of life are older, rarer, and are not exposed to postnatal risk factors (9). At this point, we know very little about the etiology of perforations in these patients (except that they also have a high incidence of muscularis externa necrosis on pathologic examination). The more common demographic is the ELBW infant who acquires SIP between days 4-14, or later if the presentation is occult.

Antenatal indomethacin? A recent retrospective cohortbased meta-analysis was performed looking at the use of antenatal indomethacin (AI) and outcomes (43). In this study, the authors found an association between NEC-like illnesses and AI given shortly before birth (SIP was not available as an outcome in all the studies analyzed). However, closer inspection of this analysis reveals that the studies driving the association were those containing ELBW infants, whereas those with larger infants showed no such association (7). These 
findings suggest that antenatal indomethacin, given close to the time of birth, may increase the risk of SIP (similar to EUI).

Intrauterine growth restriction, twins, and oligohydramnios? There is no hard data to support the supposition that growth-restricted or growth-competed infants have increased risks of SIP, but no one has ever looked specifically at these prenatal relationships in low birth weight cohorts (in which accurate dating and somatic measurements are challenging). Low birth weight infants who are intrauterine growth restriction (IUGR) may be as vulnerable to perforation as ELBW infants, for much the same reasons (the author's speculation is that they all have critically thin intestinal submucosa). Premature twins and infants with oligohydramnios may also have decreased mesenteric growth potential and, thus, predispositions to vulnerability.

\section{HOW DO STEROIDS AFFECT THE ILEUM?}

Skewed trophism (submucosa thinning + mucosal hyperplasia). Neonatal mouse models of dexamethasone effect have been used to survey growth factor systems within the ileum by immunochemistry (44-46). Two such systems have been demonstrated to be dramatically altered by steroids in the first $48 \mathrm{~h}$ of treatment and their redistribution correlates well with quantitative models of steroid-induced mucosal hyperplasia and submucosal thinning.

\section{The Insulin-Like Growth Factors-I and -II (IGF-I and IGF-II)}

$\boldsymbol{I G F}-\boldsymbol{I}$. The ileal IGF system is markedly altered by dexamethasone (44). IGF-I is abundant in mesenchymal tissues within the neonatal ileum (both human and mouse), but diminishes with steroid exposure and is redistributed to the villus lamina propria and intraepithelia basolateral spaces. This redistribution is thought to occur via IGF binding proteins (IGFBPs)-2, $-3,-4$, and -5 that reside in the serum and adhere to proteins within the mesenchymal extracellular matrix. IGFBPs bind IGF-I very tightly, but are freed by cathep$\sin \mathrm{L}$, a steroid-responsive lysosomal protease that is known to be secreted by intestinal epithelial cells (47). In a rat ileal intestinal cell model, steroid treatment increases IGFBP-2 proteolysis through cathepsin $\mathrm{L}$ induction and increases cell migration through increased IGF availability $(45,48)$. In neonatal ileum, steroid treatment results in the accumulation of IGFBP-2, $-3,-4$, and -5 proteolytic fragments (but not -1 and -6), similar to the accumulation of IGFBP-2 in the steroid treated cell culture model (summarized in Fig. 1) (48).

Steroids also elongate villus length and induce mucosal hyperplasia, so a significant aspect of their effect involves a mass migration of new and existing basal epithelial cells up the villi (49). When all of these components are pieced together, a steroid-induced system of IGF transport from the submucosa up to the intervillus space becomes apparent. Intestinal epithelial cells crawl up the villus, secreting cathep$\sin \mathrm{L}$ as they go. The cathepsin L liberates IGF from IGFBPs in the underlying matrix. The IGF binds to the IGF receptor and is obligatorily endocytosed (as is the carboxyl fragment of the IGFBP that bound it). The global result is villus elongation
A
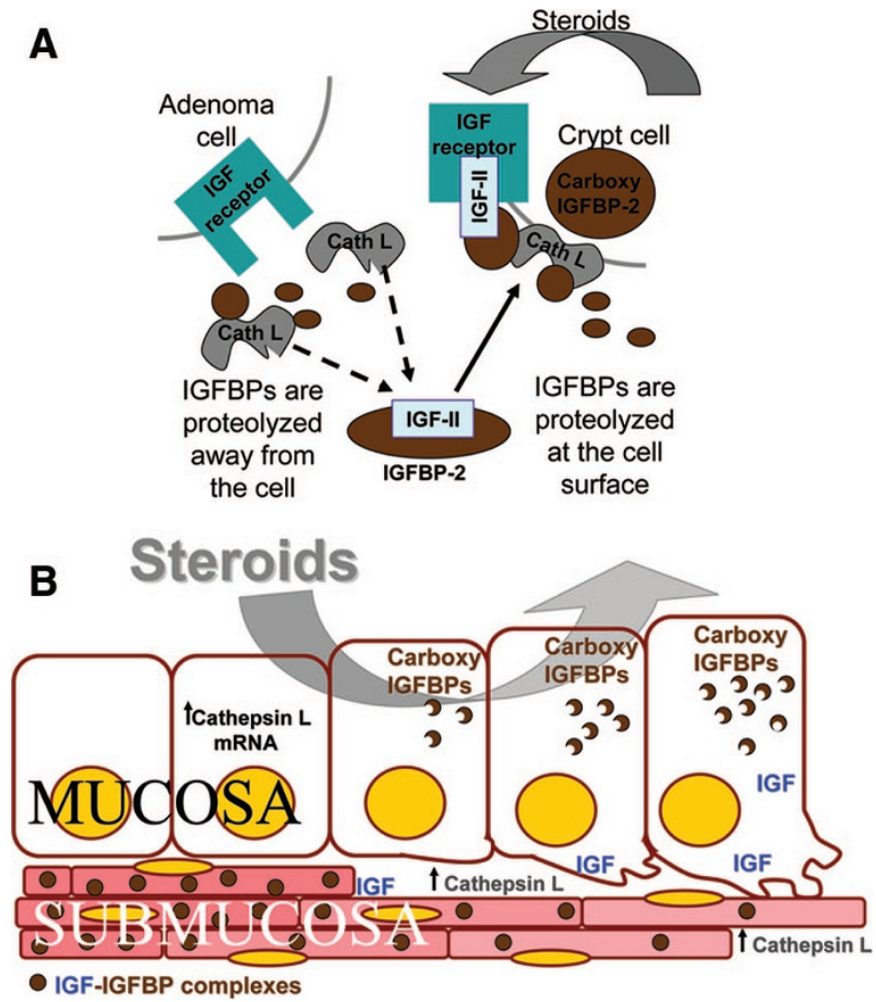

Figure 1. A. Schematic of rat ileal crypt cells (IEC-18 cells) grown in serum free culture conditions. IEC-18 culture in serum free media results in spontaneous senescence of crypt cells into adenoma cells. This senescence is attenuated by steroids, which alter insulin-like growth factor (IGF) metabolism at the cell surface. One discrete difference between the crypt and adenoma cell phenotypes is how they cleave IGF-binding protein-2 (IGFBP-2). This is the predominant IGFBP-2 in this culture model, which saturates the binding of IGF-II (the predominant IGF in this model). Crypt cells have cathepsin $\mathrm{L}$ adherent to their cell surface. This lysosomal protease is usually secreted by intestinal cells, but at the cell surface it is a potent IGFBP-specific protease, resulting in catabolism of IGBFP-2, activation of the IGF receptor, and internalization of the residual carboxyl-IGFBP-2 fragment. Steroids increase cathepsin L transcription in IEC-18 cell culture and accentuate IGFBP-2 catabolism at the crypt cell surface. $B$. Schematic of IGFBP catabolism following steroid exposure in the neonatal ileum. Similar to the IEC-18 cell culture model, steroid exposure in the newborn rat ileum results in de novo accumulation of carboxyl-IGFBP-2 in intestinal epithelial cells (as well as IGFBPs $-3,-4$, and -5). IGF-I also accumulates inside the same cells, with the same distribution. Cell culture and in vivo models demonstrate that steroids accelerate intestinal epithelial cell migration up the villus through an IGF-dependent mechanism, consistent with the cathepsin L induction mechanism portrayed in this model. In this model, IGF-IGFBP complexes are stripped from the extracellular matrix (represented as elongated rectangularshaped fibroblasts), thinning it and its supporting submucosa via the mass action of many epithelial cells migrating along the same matrix. The loss of mesenchymal IGF-IGFBP results in submucosal thinning.

at the expense of submucosal thickening (an aspect born out in studies of IGF over-expressing $v s$ null mice). It is one of the most dynamic systems of growth factor regulation ever investigated.

IGF-II. The regulation of IGF-II by steroids in ileal crypt cells has proven to be even more unusual. CREG (cellular repressor of E1A-stimulated genes) is a glyco-phosphoprotein that is increased by steroids in cultured ileal crypt and neonatal ileal epithelial cells (50). It enhances IGF-II abundance by binding IGFR2 (the type-2 IGF receptor) and enhancing its destruction (Fig. 2). IGF-II is most abundantly localized by 


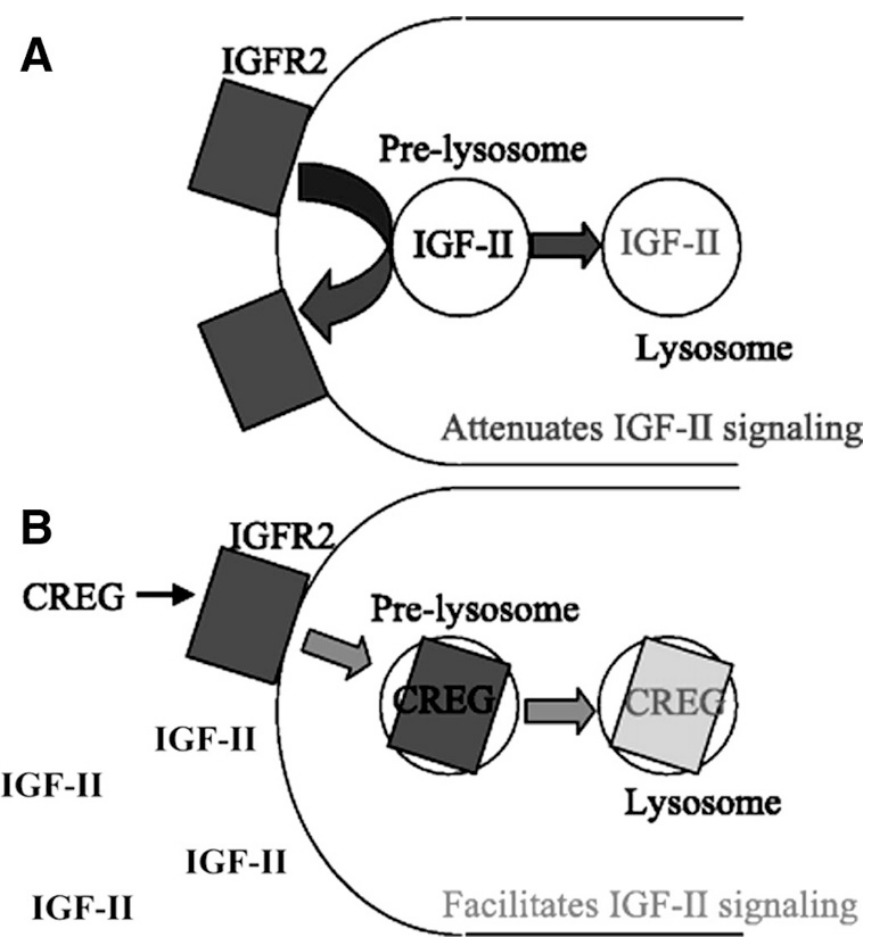

Figure 2. Schematic of steroid-induced IGF type-2-receptor (IGFR2) depletion in neonatal ileal epithelial cells. Steroids induce cellular repressor of E1A-stimulated genes (CREG), a secreted phosphoglycoprotein that adheres to the extracellular glycocalyx, and diminishes the IGFR2. CREG, like IGF-II, binds to IGFR2 with high affinity. IGF-II is normally released by IGFR2 in the lysome. We postulate that CREG binds irreversibly to IGFR2, thereby driving it to the lysome and facilitating its destruction. This mechanism would increase IGF-II availability at the cell surface, since IGFR2 specifically competes with the IGF receptor for IGF-II.

immunohistochemistry within endosomal compartments of crypt cells in neonatal ileum, consistent with its role as a stem and progenitor cell mitogen. Thus, the steroid effect on IGF-II through CREG is postulated to promote mucosal hyperplasia by driving crypt cell mitosis. This process could be further accentuated by catabolism of IGFBPs with cathepsin L, which would decrease competition for IGF-II binding (making IGF-II even more available to the IGF receptor).

\section{The Epidermal Growth Factor Family}

Transforming growth factor-alpha. Immunohistochemistrical comparisons of dexamethasone and untreated ileum from neonatal mice and ELBW infants reveal a near complete loss of transforming growth factor-alpha (TGF- $\alpha$ ) in the muscularis externa after dexamethasone treatment $(51,52)$. In contrast, other members of the epidermal growth factor (EGF) family and the EGF receptor are changed very little by steroids. This change occurs in as little as $48 \mathrm{~h}$, suggesting both transcriptional and degradational regulation. Although the full consequences of these changes are unknown, TGF- $\alpha$ is an anti-apoptotic factor and its loss likely permits the focal necrosis of smooth muscle cells that is commonly observed with SIP.

EGF-receptor signaling. Hydrocortisone has been demonstrated to potentiate EGF-dependent signaling in cultured intestinal epithelial cells (53). As with the IGFs, this steroid- induced potentiation results in increased cell proliferation and enhanced cell migration. It is possible that this potentiation is mediated at least, in part, by IGFs because the EGF and IGF signaling pathways have common down stream intermediaries. In vivo, the site where this effect is thought to be most potent is within the crypts, because this is where EGF-receptor labeling is the most intense with immunohistochemistry (summarized in Fig. 3).

\section{Nitrosyl Biology}

Depletion of neuronal nitric oxide synthase. Dexamethasone treatment of neonatal mice results in a loss of depletion of neuronal nitric oxide synthase (nNOS) in homogenized ileum (46). Immunolocolization of nNOS demonstrates that the bulk of this enzyme is found in the submucosa, where neurons pass on the way toward their connections with smooth muscle.

Depletion of inducible nitric oxide synthase. Dexamethasone treatment of neonatal mice results in a loss of depletion of inducible nitric oxide synthase (iNOS) in homogenized ileum (46). Immunolocalization of iNOS demonstrates that the bulk of this enzyme is found in the submucosa and lamina propria, where blood vessels track. There is no evidence that iNOS contributes to SIP but since it behaves almost identically to nNOS, this seems a moot point.

\section{CONTROL}

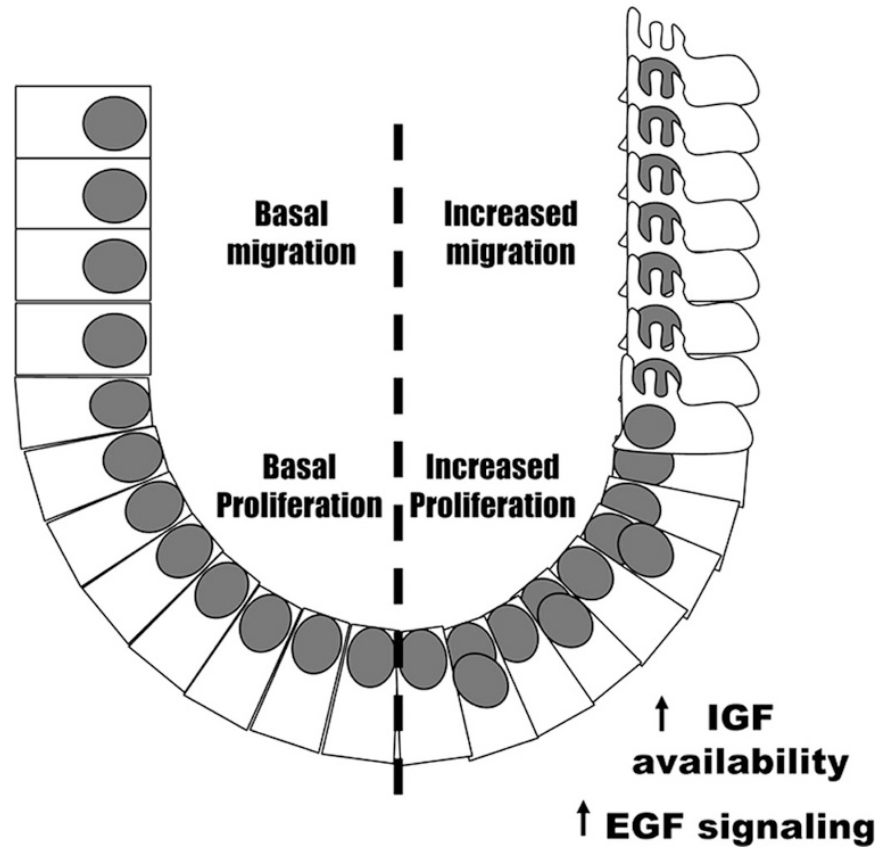

Figure 3. Schematic illustrating the effect of steroids on neonatal ileal crypt cell dynamics. Steroids have been demonstrated to increase IGF availability and to increase epidermal growth factors (EGF) receptor-mediated signaling in both cell and animal models. These events are associated with mucosal hyperplasia that is driven by two key mechanisms: 1) increased crypt cell proliferation and 2) increased cell migration up the villus. Both of these events are sensitive to each of the growth factor systems and have been demonstrated to be a affected by them specifically and synergistically in other model systems. 


\section{HOW DO STEROIDS AND INDOMETHACIN AFFECT THE ILEUM IN COMBINATION?}

Skewed trophism (no effect). The addition of indomethacin has little or no known effect on the steroid-induced trophisms associated with IGFs or EGF signaling (53). Many of the observed effects have been documented in ELBW infants that have seen both drugs or in cell culture models that included both drugs (51). In both cases, little or no additional effect has been seen above that of steroids with the addition of indomethacin.

Nitrosyl biology. Indomethacin does add a wrinkle to nitrosyl biology. Forty-eight hours of indomethacin therapy causes depletion of endothelial NOS (eNOS) within the neonatal mouse ileum (46). Thus, dexamethasone plus indomethacin together result in an almost global depletion of NOS isoforms within the neonatal ileum. Comparison of nitrosylation species within homogenized ileums using a vanadium chloride chamber demonstrates that combination treated mice have about $80 \%$ of the nitrosyl-thiols compared with controls. Therefore, one can roughly estimate that endogenous NOS produces about $20 \%$ of the covalently bound NO in ileum (with the bulk being derived from luminal contents and $\mathrm{Hb}$ transport). Although this may seem like a small percentage, that $20 \%$ may be the most biologically relevant subset. For example, SP-1 is an important transcription factor for TGF- $\alpha$ that requires nitrosylation for activation (54). Depletion of both or all NOS isoforms may be sufficient to inactivate SP-1 in smooth muscle and reduce TGF- $\alpha$ transcription. In support of this hypothesis, anti-S-nitrosylation antibodies stain ileal smooth muscle nuclei vigorously, but are abrogated by 2 days of dexamethasone treatment or by mercurial-reduction of S-nitrosylation bonds (46) (see Fig. 4).

Altered motility. Depletion of endogenously produced NO also has an effect on intestinal motility. In dexamethasonetreated eNOS null mice (a surrogate for indomethacin treatment), profound dysmotility occurs throughout the intestine (46). First, pyloric contracture occurred by 2 days of treatment (with $100 \%$ mortality on the third day). Second, there is reduced peristalsis in the distal small intestine. nNOS is known to be a crucial regulator of intestinal smooth muscle relaxation and nNOS null mice have a high incidence of pyloric stenosis. However, these findings illustrate that neonatal tissues have considerable crosstalk in NOS function and that pharmacologic depletion of multiple isoforms is required before $100 \%$ of mice display dysmotility. In addition, forced volume perfusion experiments demonstrated that dexamethasone-treated segments of intestine were more vulnerable to perforation than their eNOS null controls (consistent with the hypothesis that indomethacin might not be an independent cause of perforations) (46) (see also Fig. 5).

\section{WHAT ROLE MIGHT INFECTION PLAY?}

Retrospective clinical cohort studies have identified Candida and S. epidermis as the two most common pathogens associated with SIP (7). Positive cultures are usually acquired from the peritoneum but can also grow from the blood, and in one study, Candida was also grown from the placentas of a
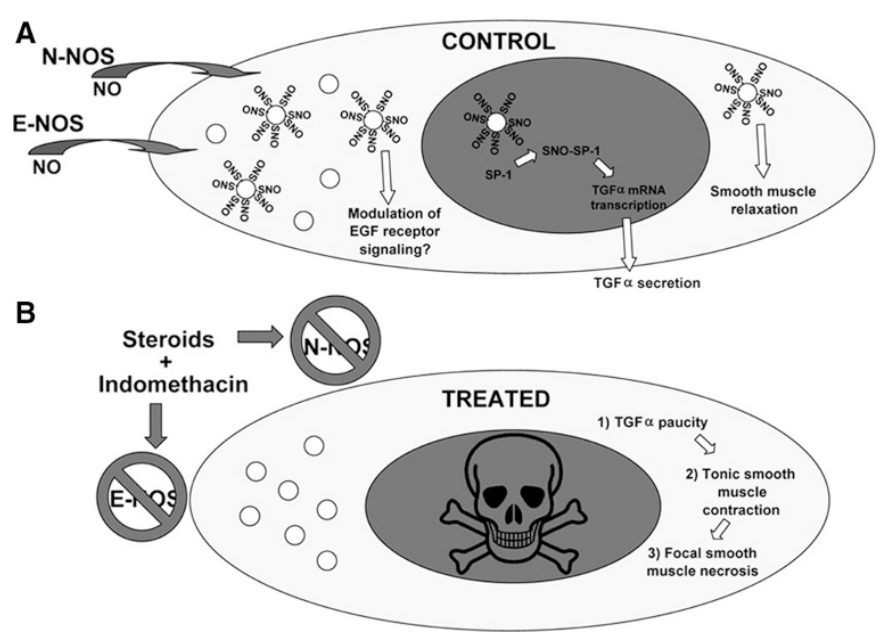

Figure 4. Schematic of the combination treatment effect of steroids and indomethacin upon ileal smooth muscle cell physiology. Neuronal nitric oxide synthetase (nNOS) and endothelial nitric oxide synthase (eNOS) produces nitric oxide (NO) from L-arginine. The resulting NO gas is fixed as S-nitrosyl species (SNOs) to proteins that have free thiols. In many cases, these thiols are found protruding from the membranes of intracellular vesicles that are subsequently trafficked throughout the cell. Thus, SNOs represent an intracellular form of NO that can be trafficked to specific targets. Some functions of NO within smooth muscle cells include regulation of contracture relaxation and induction of TGF $\alpha$ synthesis (through SP-1). Steroids abrogate transcription of nNOS and cause subsequent loss of nNOS protein in newborn mouse ileum. Likewise, indomethacin diminishes eNOS protein through an unknown mechanism. Together, the two drugs result in an almost total loss of detectable NOS in newborn mouse ileum. There is a concomitant loss of smooth muscle TGF $\alpha$ and distal intestine motility, consistent with a "two-hit" model of effect. A model of forced volume infusion has demonstrated that animals with two hits are significantly more vulnerable to perforation than animals with a single hit to the NOS system.

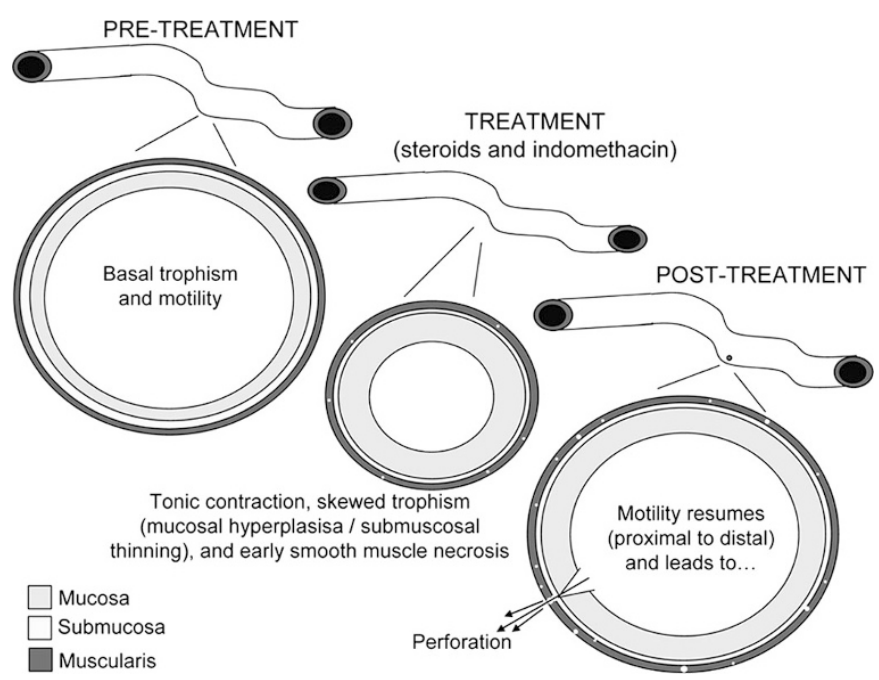

Figure 5. Schematic illustrating the timing of relevant events in spontaneous intestinal perforation. Note that perforation occurs after the window of treatment, after mucosal hyperplasia and submucosal thinning and after initial evidence of focal necrosis. The key event in the timing of perforation is the resumption of motility, which occurs proximal to distal, thereby forcing luminal gas into the fragile ileum and risking over-distention of a thinned, compromised bowel wall.

couple of SIP cases. Chorioamnionitis is associated with elevated cortisol levels, which was associated with SIP in a secondary analysis of an EPS RCT (55). The pathogens grown after perforation are thought to be opportunistic organisms 
that have escaped through the perforation into the peritoneum or blood stream. This is based primarily on the 1999 Gordon manuscript from which all infants with SIP were culture negative and all pathology specimens were examined for fungal hyphae and found to be negative. At least from this study, it seems likely that these organisms are not directly involved with some perforations. It is possible that a direct infectious mechanism for SIP might exist, but at this time, there is no basic or sufficiently rigorous clinical science to support such a postulate.

Does a PDA contribute to SIP or does it persist because of SIP? PDAs have been associated with SIP in several large cohorts. There is limited data available to determine whether PDAs might contribute to SIP or conversely if SIP might predispose to PDA. In a secondary analysis of the Pediatrix database, PDA management was divided by those who were treated early with indomethacin, not treated, or treated early with ligation to determine whether any of these three subcohorts might have an association with SIP (56). Among infants with both SIP and PDA, there was an association between SIP and early indomethacin exposure but no associations within ligated or untreated sub-cohorts. These findings were most consistent with the postulate that SIP causes persistence of PDAs.

Is neonatal ibuprofen the answer? Many centers are preferentially using neonatal ibuprofen for PDA closure because it has less effect upon mesenteric blood flow than indomethacin. There may be real advantages to this, in particular with regard to feeding intolerance (if clinicians feed through their therapy). However, with respect to SIP, the expectation seems to be that neonatal ibuprofen will translate into fewer perforations (because of the belief that SIP arises from mesenteric ischemia). Thus far, there has been no compelling evidence for this specific practice shift, including a recent meta-analysis of randomized trials that failed to find a reduction in SIP as a secondary outcome when comparing ibuprofen with indomethacin (57). The two most important variables for nonsteroidal anti-inflammatory (NSAID) association with SIP to date have been that of timing (i.e. early exposure) and coadministration with steroids. Although the former strategy is commonly used with both NSAIDs, the latter was once common off label practice with indomethacin but has been rare in RCTs since the introduction of ibuprofen. This makes comparison of older indomethacin trials with newer ibuprofen trials problematic, because such comparisons likely favor ibuprofen. Exuberance for ibuprofen as a means for SIP reduction is perplexing given the limitations of the data we have available. This unsubstantiated optimism could theoretically enhance SIP risk if the introduction of ibuprofen increased early NSAID therapy within a clinical practice currently using indomethacin cautiously or judiciously.

\section{CONCLUSIONS}

Despite widespread belief to the contrary, there is no evidence that SIP occurs because of mesenteric ischemia. All current animal and cell culture models point to the constellation of skewed trophism, depleted nitrosylation, and aberrant motility. The possibility of a direct infectious cause for SIP remains untested but Candida funisitis is a possible adjunct etiology that deserves further study. Little is known about prenatal risk factors, but late administration of indomethacin in the soon to be born ELBW infant may be a risk factor and is an area ripe for study. Finally, steroids administered with NSAIDs in the first days of life appear synergistic in their capacity to increase SIP, thus any and all combinations of these drugs should be rigorously avoided in our lowest birth weight infants.

\section{REFERENCES}

1. Ehrlich PF, Sato TT, Short BL, Hartman GE 2001 Outcome of perforated necrotizing enterocolitis in the very low-birth weight neonate may be independent of the type of surgical treatment. Am Surg 67:752-756

2. Moss RL, Dimmitt RA, Barnhart DC, Sylvester KG, Brown RL, Powell DM, Islam S, Langer JC, Sato TT, Brandt ML, Lee H, Blakely ML, Lazar EL, Hirschl RB, Kenney BD, Hackam DJ, Zelterman D, Silverman BL 2006 Laparotomy versus peritoneal drainage for necrotizing enterocolitis and perforation. N Engl J Med 354:2225-2234

3. Gordon P, Rutledge J, Sawin R, Thomas S, Woodrum D 1999 Early postnata dexamethasone increases the risk of focal small bowel perforation in extremely low birth weight infants. J Perinatol 19:573-577

4. Tatekawa Y, Muraji T, Imai Y, Nishijima E, Tsugawa C 1999 The mechanism of focal intestinal perforations in neonates with low birth weight. Pediatr Surg Int 15:549-552

5. Hwang H, Murphy JJ, Gow KW, Magee JF, Bekhit E, Jamieson D 2003 Are localized intestinal perforations distinct from necrotizing enterocolitis? J Pediatr Surg 38:763-767

6. Holland AJ, Shun A, Martin HC, Cooke-Yarborough C, Holland J 2003 Small bowe perforation in the premature neonate: congenital or acquired? Pediatr Surg Int 19:489-494

7. Gordon PV, Swanson JR, Clark R 2008 Antenatal indomethacin is more likely associated with spontaneous intestinal perforation rather than NEC. Am J Obstet Gynecol 198:725

8. Gordon PV, Swanson JR, Attridge JT, Clark R 2007 Emerging trends in acquired neonatal intestinal disease: is it time to abandon Bell's criteria? J Perinatol 27:661-671

9. Attridge JT, Clark R, Walker MW, Gordon PV 2006 New insights into spontaneous intestinal perforation using a national data set: (2) two populations of patients with perforations. J Perinatol 26:185-188

10. Attridge JT, Clark R, Gordon PV 2006 New insights into spontaneous intestina perforation using a national data set (3): antenatal steroids have no adverse association with spontaneous intestinal perforation. J Perinatol 26:667-670

11. Gordon PV, Young ML, Marshall DD 2001 Focal small bowel perforation: an adverse effect of early postnatal dexamethasone therapy in extremely low birth weight infants. J Perinatol 21:156-160

12. Attridge JT, Clark R, Walker MW, Gordon PV 2006 New insights into spontaneous intestinal perforation using a national data set: (1) SIP is associated with early indomethacin exposure. J Perinatol 26:93-99

13. Garland JS, Alex CP, Pauly TH, Whitehead VL, Brand J, Winston JF, Samuels DP, McAuliffe TL 1999 A three-day course of dexamethasone therapy to prevent chronic lung disease in ventilated neonates: a randomized trial. Pediatrics 104:91-99

14. Anttila E, Peltoniemi O, Haumont D, Herting E, ter Horst H, Heinonen K, Kero P, Nykänen P, Oetomo SB, Hallman M 2005 Early neonatal dexamethasone treatment for prevention of bronchopulmonary dysplasia. Randomized trial and meta-analysis evaluating the duration of dexamethasone therapy. Eur J Pediatr 164:472-481

15. Stark AR, Carlo WA, Tyson JE, Papile LA, Wright LL, Shankaran S, Donovan EF, Oh W, Bauer CR, Saha S, Poole WK, Stoll BJ 2001 Adverse effects of early dexamethasone in extremely-low-birth-weight infants. National Institute of Child Health and Human Development Neonatal Research Network. N Engl J Med 344:95-101

16. Efird MM, Heerens AT, Gordon PV, Bose CL, Young DA 2005 A randomizedcontrolled trial of prophylactic hydrocortisone supplementation for the prevention of hypotension in extremely low birth weight infants. J Perinatol 25:119-124

17. Peltoniemi O, Kari MA, Heinonen K, Saarela T, Nikolajev K, Andersson S, Voutilainen R, Hallman M 2005 Pretreatment cortisol values may predict responses to hydrocortisone administration for the prevention of bronchopulmonary dysplasia in high-risk infants. J Pediatr 146:632-637

18. Vermont Oxford Network Steroid Study Group 2001 Early postnatal dexamethasone therapy for the prevention of chronic lung disease. Pediatrics 108:741-748

19. Kopelman AE, Moise AA, Holbert D, Hegemier SE 1999A single very early dexamethasone dose improves respiratory and cardiovascular adaptation in preterm infants. J Pediatr 135:345-350

20. Yeh TF, Torre JA, Rastogi A, Anyebuno MA, Pildes RS 1990 Early postnatal dexamethasone therapy in premature infants with severe respiratory distress syndrome: a double-blind, controlled study. J Pediatr 117:273-282

21. Shinwell ES, Karplus M, Zmora E, Reich D, Rothschild A, Blazer S, Bader D, Yurman S, Dolfin T, Kuint J, Milbauer B, Kohelet D, Goldberg M, Armon Y, Davidson S, Sirota L, Amitai M, Zaretsky A, Barak M, Gottfried S 1996 Failure of early postnatal dexamethasone to prevent chronic lung disease in infants with respiratory distress syndrome. Arch Dis Child Fetal Neonatal Ed 74:F33-F37 
22. Watterberg KL, Gerdes JS, Gifford KL, Lin HM 1999 Prophylaxis against early adrenal insufficiency to prevent chronic lung disease in premature infants. Pediatrics $104: 1258-1263$

23. Watterberg KL, Gerdes JS, Cole CH, Aucott SW, Thilo EH, Mammel MC, Couser RJ, Garland JS, Rozycki HJ, Leach CL, Backstrom C, Shaffer ML 2004 Prophylaxis of early adrenal insufficiency to prevent bronchopulmonary dysplasia: a multicenter trial. Pediatrics 114:1649-1657

24. Rastogi A, Akintorin SM, Bez ML, Morales P, Pildes RS 1996 A controlled trial of dexamethasone to prevent bronchopulmonary dysplasia in surfactant-treated infants. Pediatrics 98:204-210

25. Sinkin RA, Dweck HS, Horgan MJ, Gallaher KJ, Cox C, Maniscalco WM, Chess PR, D'Angio CT, Guillet R, Kendig JW, Ryan RM, Phelps DL 2000 Early dexamethasone-attempting to prevent chronic lung disease. Pediatrics 105:542-548

26. Roberts RS 2004 Early closure of the Watterberg trial. Pediatrics 114:1670-1671

27. Jobe AH 2004 Postnatal corticosteroids for preterm infants-do what we say, not what we do. N Engl J Med 350:1349-1351

28. Attridge JT, Herman AC, Gurka MJ, Griffin MP, McGahren ED, Gordon PV 2006 Discharge outcomes of extremely low birth weight infants with spontaneous intestinal perforations. J Perinatol 26:49-54

29. Doyle LW, Halliday HL, Ehrenkranz RA, Davis PG, Sinclair JC 2005 Impact of postnatal systemic corticosteroids on mortality and cerebral palsy in preterm infants: effect modification by risk for chronic lung disease. Pediatrics 115:655-661

30. Yeh TF, Lin YJ, Lin HC, Huang CC, Hsieh WS, Lin CH, Tsai CH 2004 Outcomes at school age after postnatal dexamethasone therapy for lung disease of prematurity. N Engl J Med 350:1304-1313

31. Nagaraj HS, Sandhu AS, Cook LN, Buchino JJ, Groff DB 1981 Gastrointestinal perforation following indomethacin therapy in very low birth weight infants. $\mathrm{J} \mathrm{Pe}$ diatr Surg 16:1003-1007

32. Alpan G, Eyal F, Vinograd I, Udassin R, Amir G, Mogle P, Glick B 1985 Localized intestinal perforations after enteral administration of indomethacin in premature infants. J Pediatr 106:277-281

33. Kühl G, Seyberth HW 1986 Intestinal perforations after enteral administration of indomethacin in premature infants. J Pediatr 108:327-328

34. Schmidt B, Roberts RS, Fanaroff A, Davis P, Kirpalani HM, Nwaesei C, Vincer M 2006 TIPP Investigators. Indomethacin prophylaxis, patent ductus arteriosus, and the risk of bronchopulmonary dysplasia: further analyses from the Trial of Indomethacin Prophylaxis in Preterms (TIPP). J Pediatr 148:730-734

35. Ragouilliaux CJ, Keeney SE, Hawkins HK, Rowen JL 2007 Maternal factors in extremely low birth weight infants who develop spontaneous intestinal perforation. Pediatrics 120:e1458-e1464

36. Coates EW, Karlowicz MG, Croitoru DP, Buescher ES 2005 Distinctive distribution of pathogens associated with peritonitis in neonates with focal intestinal perforation compared with necrotizing enterocolitis. Pediatrics 116:e241-e246

37. Robertson NJ, Kuna J, Cox PM, Lakhoo K 2003 Spontaneous intestinal perforation and Candida peritonitis presenting as extensive necrotizing enterocolitis. Acta Paediatr 92:258-261

38. Bond S, Stewart DL, Bendon RW 2000 Invasive Candida enteritis of the newborn. J Pediatr Surg 35:1496-1498

39. Adderson EE, Pappin A, Pavia AT 1998 Spontaneous intestinal perforation in premature infants: a distinct clinical entity associated with systemic candidiasis. J Pediatr Surg 33:1463-1467

40. Novack CM, Waffarn F, Sills JH, Pousti TJ, Warden MJ, Cunningham MD 1994 Focal intestinal perforation in the extremely-low-birth-weight infant. J Perinatol $14: 450-453$
41. Meyer CL, Payne NR, Roback SA 1991 Spontaneous, isolated intestinal perforations in neonates with birth weight less than $1,000 \mathrm{~g}$ not associated with necrotizing enterocolitis. J Pediatr Surg 26:714-717

42. Mintz AC, Applebaum H 1993 Focal gastrointestinal perforations not associated with necrotizing enterocolitis in very low birth weight neonates. J Pediatr Surg 28:857-860

43. Amin SB, Sinkin RA, Glantz JC 2007 Metaanalysis of the effect of antenatal indomethacin on neonatal outcomes. Am J Obstet Gynecol 197:486.e1-e10

44. Gordon PV, Price WA, Stiles AD 2001 Dexamethasone administration to newborn mice alters mucosal and muscular morphology in the ileum and modulates IGF-I localization. Pediatr Res 49:93-100

45. Herman AC, Carlisle EM, Paxton JB, Gordon PV 2004 Insulin-like growth factor-I governs submucosal growth and thickness in the newborn mouse ileum. Pediatr Res 55:507-513

46. Gordon PV, Herman AC, Marcinkiewicz M, Gaston BM, Laubach VE, Aschner JL 2007 A neonatal mouse model of intestinal perforation: investigating the harmful synergism between glucocorticoids and indomethacin. J Pediatr Gastroenterol Nutr 45:509-519

47. Gordon PV, Paxton JB, Herman AC, Carlisle EM, Fox NS 2004 Igf-I accelerates ileal epithelial cell migration in culture and newborn mice and may be a mediator of steroid-induced maturation. Pediatr Res 55:34-41

48. Gordon PV, Paxton JB, Kuemmerle JF, Fox NS 2005 A 14-kDa cathepsin L-derived carboxyl IGFBP-2 fragment is sequestered by cultured rat ileal crypt cells. Am J Physiol Gastrointest Liver Physiol 289:G79-G87

49. Gordon PV, Moats-Staats BM, Stiles AD, Price WA 2002 Dexamethasone changes the composition of insulin-like growth factor binding proteins in the newborn mouse ileum. J Pediatr Gastroenterol Nutr 35:532-538

50. Gordon PV, Paxton JB, Fox NS 2005 The cellular repressor of E1A-stimulated genes mediates glucocorticoid-induced loss of the type-2 IGF receptor in ileal epithelial cells. J Endocrinol 185:265-273

51. Gordon PV, Price WA, Stiles AD, Rutledge JC 2001 Early postnatal dexamethasone diminishes transforming growth factor alpha localization within the ileal muscularis propria of newborn mice and extremely low-birth-weight infants. Pediatr Dev Pathol $4 \cdot 532-537$

52. Gordon PV, Marshall DD, Stiles AD, Price WA 2001 The clinical, morphologic, an molecular changes in the ileum associated with early postnatal dexamethasone administration: from the baby's bowel to the researcher's bench. Mol Genet Metab 72:91-103

53. Kajanne R, Leppä S, Luukkainen P, Ustinov J, Thiel A, Ristimäki A, Miettinen PJ 2007 Hydrocortisone and indomethacin negatively modulate EGF-R signaling in human fetal intestine. Pediatr Res 62:570-575

54. Zaman K, Palmer LA, Doctor A, Hunt JF, Gaston B 2004 Concentration-dependent effects of endogenous S-nitrosoglutathione on gene regulation by specificity protein Sp3 and Sp1. Biochem J 380:67-74

55. Watterberg K 2005 Weighing statistical certainty against ethical, clinical, and biologic expediency: the contributions of the Watterberg trial tip the scales in the right direction: in reply. Pediatrics 115:1447

56. Bloom BT 2006 Attridge et al. present an analysis of a complex data set, which offers important confirmation of the differences between the clinical presentation of spontaneous intestinal perforations (SIP) and surgical necrotizing enterocolitis (see author reply). J Perinatol 26:384-386

57. Ohlsson A, Walia R, Shah S 2008 Ibuprofen for the treatment of patent ductus arteriosus in preterm and/or low birth weight infants. Cochrane Database Syst Rev 23:CD003481 